University of Texas Rio Grande Valley

ScholarWorks @ UTRGV

Civil Engineering Faculty Publications and

Presentations

$1-2021$

\title{
Kinetics and thermodynamics of thermal inactivation for recombinant Escherichia coli cellulases, cel12B, cel8C, and polygalacturonase, peh28; biocatalysts for biofuel precursor production
}

Eman Ibrahim

Ahmed Mahmoud

The University of Texas Rio Grande Valley

Kim D. Jones

Keith E. Taylor

Ebtesam N. Hosseney

See next page for additional authors

Follow this and additional works at: https://scholarworks.utrgv.edu/ce_fac

Part of the Civil Engineering Commons

\section{Recommended Citation}

Ibrahim, Eman, Ahmed Mahmoud, Kim D. Jones, Keith E. Taylor, Ebtesam N. Hosseney, Patrick L. Mills, and Jean M. Escudero. 2021. "Kinetics and Thermodynamics of Thermal Inactivation for Recombinant Escherichia Coli Cellulases, Cel12B, Cel8C, and Polygalacturonase, Peh28; Biocatalysts for Biofuel Precursor Production." Journal of Biochemistry 169 (1): 109-17. https://doi.org/10.1093/jb/mvaa097.

This Article is brought to you for free and open access by the College of Engineering and Computer Science at ScholarWorks @ UTRGV. It has been accepted for inclusion in Civil Engineering Faculty Publications and Presentations by an authorized administrator of ScholarWorks @ UTRGV. For more information, please contact justin.white@utrgv.edu,william.flores01@utrgv.edu. 


\section{Authors}

Eman Ibrahim, Ahmed Mahmoud, Kim D. Jones, Keith E. Taylor, Ebtesam N. Hosseney, Patrick L. Mills, and Jean M. Escudero 
Kinetics and thermodynamics of thermal inactivation for recombinant Escherichia coli cellulases, cel12B, cel8C, and polygalacturonase, peh28; biocatalysts for biofuel precursor production

Eman Ibrahim ${ }^{1 *}$, Ahmed Mahmoud ${ }^{2}$, Kim D. Jones ${ }^{3}$, Keith E. Taylor ${ }^{4}$, Ebtesam N. Hosseney ${ }^{5}$, Patrick L. Mills $^{6}$ and Jean M. Escudero ${ }^{7}$

${ }^{1}$ Department of Environmental Engineering, Texas A\&M University-Kingsville, Kingsville, Texas 78363, USA and Department of Botany and Microbiology, Al-Azhar University, Nasr City, Cairo 11884, Egypt; author for correspondence evengenetic@gmail.com

${ }^{2}$ Department of Environmental Engineering, Texas A\&M University-Kingsville, Kingsville, Texas 78363, USA (current address: Civil Engineering Department, University of Texas Rio Grande Valley, Edinburg, Texas 78539-2909, USA); ahmed.mahmoud@utrgv.edu

${ }^{3}$ Department of Environmental Engineering, Texas A\&M University-Kingsville, Kingsville, Texas 78363, USA; Kim.Jones@tamuk.edu

${ }^{4}$ Department of Chemistry and Biochemistry, University of Windsor, Windsor, Ontario, Canada

N9B 3P4; taylor@uwindsor.ca

${ }^{5}$ Department of Botany and Microbiology, Al-Azhar University, Nasr City, Cairo 11884, Egypt; bs_naeim25@yahoo.com

${ }^{6}$ Department of Chemical Engineering, Texas A\&M University-Kingsville, Kingsville, Texas 78363, USA; patrick.mills@tamuk.edu

${ }^{7}$ Department of Basic Sciences, St. Louis College of Pharmacy, St. Louis, Missouri 63110-1088, USA; Jean.Escudero@stlcop.edu

(C) The Author(s) 2020. Published by Oxford University Press on behalf of the Japanese Biochemical Society. All rights reserved. 
Field: Biochemistry; Topic: Enzymology (protein structure)

\begin{abstract}
Abbreviations: cel12B, cellulase-12B; cel8C, cellulase-8C; peh28, polygalacturonase-28; GH, glycoside hydrolase; Pcc, Pectobacterium carotovorum subsp. Carotovorum; CBD, carbohydrate binding domain; CMC, carboxymethyl cellulose; $\mathrm{k}_{\mathrm{d}}$, inactivation rate constant; $\mathrm{t}_{1 / 2}$, half-life; $\mathrm{D}$-value, decimal-reduction time; $E_{d}$, energy of inactivation; $\Delta \mathrm{S}$, change in entropy; $\Delta H$, change in enthalpy; $\Delta \mathrm{G}$, change in Gibbs free energy
\end{abstract}

Note: Nucleotide sequences from which the protein sequences were deduced have been deposited with the European Nucleotide Archive under the following accession numbers: for peh28, PRJEB31526; for cel8C, PRJEB31527; for cel12B, PRJEB31528. UniProt accession numbers will be assigned from these in due course. 


\section{Summary}

Lignocellulosic biomass conversion using cellulases/polygalacturonases is a process that can be progressively influenced by several determinants involved in cellulose microfibril degradation. The current paper focuses on the kinetics and thermodynamics of thermal inactivation of recombinant E. coli cellulases, cel12B, cel8C, and a polygalacturonase, peh 28, derived from Pectobacterium carotovorum sub sp. carotovorum. Several consensus motifs conferring the enzymes' thermal stability in both cel12B and peh28 model structures have been detailed earlier, which were confirmed for the three enzymes through the current study of their thermal inactivation profiles over the $20-80^{\circ} \mathrm{C}$ range using the respective activities on carboxymethylcellulose and polygalacturonic acid. Kinetic constants and halflives of thermal inactivation, inactivation energy, plus inactivation entropies, enthalpies and Gibbs free energies, revealed high stability, less conformational change and protein unfolding for cel12B and peh28 due to thermal denaturation compared to cel8C. The apparent thermal stability of peh28 and cel12B, along with their hydrolytic efficiency on a lignocellulosic biomass conversion as reported previously, makes these enzymes candidates for various industrial applications. Analysis of the Gibbs free energy values suggests that the thermal stabilities of cel12B and peh28 are entropy-controlled over the tested temperature range.

Keywords: cellulase; polygalacturonase; catalysis; thermodynamics; kinetics. 
Study of lignocellulosic biomass composition and its enzymatic processing has led to progress in the production of biofuels and of the biocatalysts themselves $(1,2)$. In nature, biomass decomposition takes place through a group of glycosyl hydrolases, which have various tolerances to thermal, acid or alkaline conditions (2). Endo- and exo-glucanases from various sources have been characterized in decomposition of biomass cellulose in the presence or absence of $\beta$-glucosidase $(3,4)$. Pectin homogalacturonans from various biomasses undergo hydrolysis via endo- and exo-polygalacturonases (5). Loss of enzymatic activity as the hydrolysis progresses on cellulosic or lignocellulosic substrates has been attributed to various inhibitory factors and enzyme thermal-instability (๑). Kinetics of enzyme activity loss could provide information on the complexities and the stages following denaturation comprising a set of complex molecular events, i.e. the unfolding of enzymes' tertiary structure (7). An enzyme's capacity to resist thermal unfolding in the absence and presence of the substrate can be elucidated by analysis of a detailed thermostability profile $(7,8)$. Studies on polygalacturonase inactivation kinetics and thermodynamics showed negative entropy changes of both crude and partially purified enzymes, attributed to enzyme structural changes, i.e. enzyme unfolding, or to an effect of the surrounding medium (9). Knowledge of phenomena influencing an enzyme's thermal stability is crucial from a commercial perspective (10). For example, the presence of a polymethylgalacturonate or potassium salts improved the stability of certain polygalacturonases/pectinases (9) and cel7A cellulases showed enzyme-substrate complex association to be entropy-controlled, whereas the intermediate enzyme-substrate dissociation cycle was controlled by enthalpy (11). The presence of carbohydrate binding domains (CBDs) causing an increase in the free energy barrier was reported for the enzyme-substrate dissociation cycle of cel7Acellulases and in these systems analyses of free energy barriers have provided details for enzyme interfacial catalysis and mechanism (11).

Our previous work focused on the construction, expression, biochemical characterization, structural modeling and potential industrial application to lignocellulosic biomass conversion of Escherichia coli recombinant cellulases (cel8C and cel12B) and polygalacturonase (peh28) (12-14). Evaluation of 
conserved amino acids in catalytic and non-catalytic sites of cel12B and peh28 structures revealed the presence of $\operatorname{Pro}^{170}$ and $\mathrm{Arg}^{96}$, respectively, that correlate with thermal stability and processivity functions as modeled in related protein sequences (14). The recombinants, in combination with a related $\beta$ glucosidase, efficiently released glucose, cellobiose and galacturonic acid hydrolysis products from grapefruit processing waste, confirming their efficacy in production of biofuel precursors (12).

In this study, residual enzyme activities were determined in the $20-80^{\circ} \mathrm{C}$ range to construct thermal profiles for the same semi-purified extracts of cel12B, cel $8 \mathrm{C}$ and peh 28 studied previously. The profiles furnished rate constants $\left(\mathrm{k}_{\mathrm{d}}\right)$ for the enzymes' thermal inactivation, as well as the respective half-lives $\left(\mathrm{t}_{1 / 2}\right)$ and decimal-reduction times (D-values). Molecular insight into the enzymes' inactivation behavior was provided from the thermodynamic parameters (derived from Arrhenius plots), inactivation energy $\left(\mathrm{E}_{\mathrm{d}}\right)$ plus changes in entropy $(\Delta \mathrm{S})$, enthalpy $(\Delta \mathrm{H})$ and Gibbs free energy $(\Delta \mathrm{G})$. Structural models designed earlier for cel12B and peh28 were correlated with the current thermal stability results for these two enzymes. An explanation is provided for apparent disparities in thermal inactivation shown among the recombinants. In so doing, the study highlights the possible industrial applications for lignocellulosic biomass conversion by cel12B and peh28, and the candidacy for additional genomic studies which might beneficially modify the cel8C system for the same application.

\section{Materials and methods}

\section{Enzyme preparations and activity determinations}

Cel12B, cel8C and peh28 were individually expressed and purified from overnight-grown E. coli transformed with $P c c-c e l B,-c e l C$ and -peh recombinant plasmids, respectively, at $37^{\circ} \mathrm{C}$ in $100 \mu \mathrm{g} / \mathrm{mL}$ ampicillin containing Luria-Bertani broth, following the protocol previously published (14). Polygalacturonase activity was determined for peh28 on polygalacturonic acid (sodium salt from citrus fruit, $\geq 75 \%$ titration, cat. no. P3850, Sigma-Aldrich, St. Louis, MO), using the Nelson-Somogyi (NS)spectrophotometric assay protocol $(15,16)$, with copper and arsenomolybdate reagents, where the change 
in the absorbance for the reduced hydrolysate system was measured at $520 \mathrm{~nm}$ using an Odyssey spectrophotometer, model DR/2500 (cat. no. 5900000, Hach, Loveland, CO) and equilibrated versus Aspergillus niger pectinase (E.C.3.2.1.15) (cat. no. 17389, Sigma-Aldrich, St. Louis, MO) activity standard reference on the same substrate as previously described (14). One unit of polygalacturonase activity is defined as the amount of enzyme releasing $1 \mu$ mol of reducing sugars per minute from polygalacturonic acid under the assay conditions. The cellulolytic activities of cel12B and cel8B, were detected on carboxymethyl cellulose (CMC), following a protocol modified by Miller (17), using 3,5dinitrosalicylic acid (DNS). The absorbance of the hydrolysate reducing sugars, was determined at 540 nm using $A$. niger-1,4-(1,3:1,4)- $\beta$-D-Glucan 4-glucanohydrolase (E.C.3.2.1.4) (cat. no. 22178, SigmaAldrich, St. Louis, MO) activity calibration standard. One unit of cellulase activity is defined as the amount of enzyme releasing $1 \mu \mathrm{mol}$ of reducing sugars per minute from $\mathrm{CMC}$ under the assay conditions.

\section{Thermal stability profiles for cel8C, cel12B and peh28}

Enzyme residual activities after one-hour thermal treatment at several temperatures within the $20-80^{\circ} \mathrm{C}$ range were evaluated for cel8C, cel12B or peh28 using the respective optimum assay conditions at $45^{\circ} \mathrm{C}$ and $\mathrm{pH} 5.4$ on $\mathrm{CMC}(25 \mathrm{mg} / \mathrm{mL})$ or polygalacturonic acid $(4 \mathrm{mg} / \mathrm{mL})$ and compared to thermally untreated controls, using equation 1. Total reducing sugars accumulated at each temperature were measured spectrophotometrically following the same assay method described for cellulase and polygalacturonase.

$R=(A / A o) / 100$

Where $R$ is the residual enzyme activity as a percentage, $A$ is the enzymatic activity in thermally treated fractions and $A o$ is the enzymatic activity in a thermally-untreated control. 


\section{Kinetic and thermodynamic study of thermal inactivation of cel12B, cel8C and peh28}

Cel12B, cel8C and peh28 were characterized for their kinetics and thermodynamics of denaturation due to thermal inactivation at 37,50 or $60^{\circ} \mathrm{C}$ over $24 \mathrm{~h}$ in the appropriate buffer, $50 \mathrm{mM}$ sodium citrate for cel12B, cel8C and $50 \mathrm{mM}$ sodium acetate for peh28, both at $\mathrm{pH} 5.4$, where the enzymes' residual activities were periodically determined relative to thermally untreated controls, using the assays described above for cellulases and polygalacturonase.

An enzyme thermal inactivation rate constant $\left(k_{\mathrm{d}}\right)$ was calculated at each temperature using equation 2 , based on fitting a first-order kinetic model to the data for enzyme activity losses with CMC, for cel12B and cel8C, or with polygalacturonic acid, for peh28.

$$
\ln \left(A_{t}\right)=-k_{d} t+\ln \left(A_{0}\right)
$$

Where, $A_{t}$ is the residual enzyme activity at time $t$ and $A_{0}$ is the initial enzyme activity in the thermally untreated control.

The times required for each enzyme to lose half of its activity $\left(t_{1 / 2}\right)$ and $90 \%$ of its activity (D value) at a specific temperature were calculated using equations 3 and 4 , respectively.

$$
\begin{aligned}
& t_{1 / 2}=\ln (2) / k_{d} \\
& D=\ln (10) / k_{d}
\end{aligned}
$$

Thermodynamic parameters of thermal inactivation determined on $\mathrm{CMC}$, for cel12B and cel8C, or polygalacturonic acid, for peh28, were: the energy of inactivation $\left(E_{d}\right)$, change in enthalpy $(\Delta H)$, change in Gibbs free energy $(\Delta \mathrm{G})$, change in entropy $(\Delta \mathrm{S})$, due to the denaturation at each defined temperature, which were calculated following Bhatti et al. (18) and Batista et al. (19), following Arrhenius' law that was utilized for quantification of $\mathrm{E}_{\mathrm{d}}$ for each enzyme as in equation 5. 


$$
\ln k_{\mathrm{d}}=\ln k_{0}-E_{\mathrm{d}} /(R T)
$$

Where $k_{0}$ is the Arrhenius constant, $k_{\mathrm{d}}$ is the inactivation rate constant at the studied temperature, $R$ is the universal gas constant, $8.3145 \mathrm{~J} \mathrm{~mol}^{-1} \mathrm{~K}^{-1}, T$ is the absolute temperature. Therefore, the energy of inactivation can be obtained from the slope of regression of inactivation rate constant $\left(\mathrm{k}_{\mathrm{d}}\right)$ versus the reciprocal of absolute temp which is equal to $E_{d} / R$.

The variation in the $\Delta \mathrm{H}$ and the change in $\Delta \mathrm{G}$ values were calculated with equations 6 and 7 , respectively, using the respective $\mathrm{E}_{\mathrm{d}}$ values at temperatures $\mathrm{T}$.

$$
\begin{aligned}
& \Delta H=E_{d}-R T \\
& \Delta G=-R T \ln \left(k_{d} h / k T\right)
\end{aligned}
$$

Where $h$ is Planck's constant, $6.6262 \times 10^{-34} \mathrm{~J} \mathrm{~s}$, and $k$ is Boltzmann's constant, $1.3806 \times 10^{-23} \mathrm{~J} \mathrm{~K}^{-1}$.

The $\Delta \mathrm{H}$ and $\Delta \mathrm{G}$ values obtained at temperature $\mathrm{T}$ were used for the calculation of $\Delta \mathrm{S}$, equation 8 .

$$
\Delta S=\frac{(\Delta H-\Delta G)}{T}
$$

\section{Statistical Analysis}

GraphPad Prism 6.0 (GraphPad Software Inc., La Jolla, CA) was utilized throughout for corresponding analysis of variance (ANOVA) for all measurements in triplicate, where the incorporated Tukey one-way post-test was selected.

\section{Results and discussion}




\section{Thermal stability profiles for cel8C, cel12B and peh28}

Residual enzyme activities were evaluated following one-hour incubation at several temperatures within the $20-80^{\circ} \mathrm{C}$ range, compared to thermally untreated controls, given in Fig. 1. Cel8C showed progressive activity loss at higher temperatures, a characteristic that has been seen with other GH-8 cellulases (14). In contrast, the thermal stability profiles for cel12B and peh28 were shifted to higher temperatures $\left(8-10^{\circ} \mathrm{C}\right.$ at the mid-point) (Fig. 1). Moderate thermal stability was also found in the $60-70^{\circ} \mathrm{C}$ range for cel12B and peh28, which retained 70 and $57 \%$ of their maximal activities at $60^{\circ} \mathrm{C}$ and $65^{\circ} \mathrm{C}$, respectively. Thermal stabilities of cel12B and peh28 have been reported previously with several GH-12 cellulases/endoglucanases (20-22) and GH-28 polygalacturonase/pectinases (23-25). Significant residual activities were also found for cel12B and peh28 as high as $70-80^{\circ} \mathrm{C}$ (Fig. 1). The peh28 residual activity at $80^{\circ} \mathrm{C}$ was $15 \%$, which is three times higher than the exo-polygalacturonase (exo-PG) from Penicillium notatum (26). However, these authors reported improved activity at $80^{\circ} \mathrm{C}$ for the immobilized exo-PG, which was attributed to the polymeric Na-alginate matrix imposing protection from denaturation (26).

\section{$\underline{\text { Insert Figure } 1}$}

As the temperature increases, enzymes may undergo conformational changes such as those reported for cel12A from Rhodothermus marinus (27), which suggests that increased proline residue content and decreased glycine residue content stabilized the molecule against denaturation. The role of GLU34 and PRO35 residues located at the C-terminal for cel12A from $R$. marinus, were also reported as bridging the enzyme central protein region through hydrogen bonds, thereby conferring stability (28). Analogous proline and glutamine residues were detected in the cel12B model structure (Supplementary Fig. 1a), which could similarly contribute to its relative thermal stability over $20-65^{\circ} \mathrm{C}$. However, the enzyme's progressive loss of activity at $70-80^{\circ} \mathrm{C}$ is indicative of thermal unfolding $(26,29,30)$.

On the other hand, the role of a CBD in facilitating enzyme thermal stability for cel7A from Clostridium phytofermentans was associated with elevation in the enzyme's melting point (31). The direct role of 
CBD-3 in the stability of an endoglucanase from C. phytofermentans has also been reported (32). A CBD (CBD-II) was found in the cel12B model structure, residues 279-378 (but not in the model structure of cel8C) (14) which could similarly provide a benefit to thermal stability. Analogous CBDs in pectinases have been reported (33) but the previous study did not find one in peh28 (14). However, van Solingen et al. (34) reported that the removal of a CBD from Streptomyces sp. 11AG8 Cel12A, did not influence the enzyme activity and/or stability.

The focus of another study by Palomaki et al. (35) was to identify protein target motifs for a polygalacturonase (PehA) from Pcc. A residue replacement, CYS99SER, in the protein peripheral loop region of the enzyme's three-dimensional structure was identified to be essential for enzyme stability because loss of enzyme activity was observed upon its mutation. The indirect major role of TRP135 in the same loop region, hydrophobic packing with adjacent residues, was also deduced by analogous experiments. Studies on another motif target at the C-terminus revealed the roles of conserved ASN371 and non-conserved VAL372 and VAL374, in hydrophobicity; in addition, TRP367ARG and VAL342ALA mutations allowed correlation of their functions in enzyme stability and/or protein conformation (35). Likewise, valine, tryptophan and asparagine residues were found in the peh28 model structure (Supplementary Fig. 1b) which predict their contribution to its thermal stability observed at temperatures higher than $45^{\circ} \mathrm{C}$.

With respect to the single-residue contributors to stability noted in the preceding paragraphs, cel12B, cel8C and peh28 share no broad structural homology and thus the previous structural modeling study (14) had no points of reference to search for potentially-stabilizing conserved residues. The putative roles of these inferred target residues in the stability of cel12B and peh28 could be tested using site-directed mutagenesis.

\section{Kinetics of thermal inactivation of cel12B, cel8C and peh28}


Enzyme residual activities were evaluated for the cel12B, cel8C and peh28 following their thermal treatments at 37,50 and $60^{\circ} \mathrm{C}$ over $24 \mathrm{~h}$ at $\mathrm{pH} 5.4$, as compared with thermally untreated controls and results are shown in Fig. 3 a-c, respectively. Lower temperatures were not tested because it was only at $37^{\circ} \mathrm{C}$ and beyond that the profiles (Fig. 1) differed significantly. The remaining activities of cel $8 \mathrm{C}$ were much lower compared with the other two enzymes' activities, for example, it had $65 \%$ activity remaining after $8 \mathrm{~h}$ at $37^{\circ} \mathrm{C}$, while no activities were observed after $6 \mathrm{~h}$ at $50^{\circ} \mathrm{C}$ and $3 \mathrm{~h}$ at $60^{\circ} \mathrm{C}$ (Fig. 2b). The rapid decline in the activity of cel $8 \mathrm{C}$ at the latter temperatures is quite evident. Such differences in thermal stability, seen here for cel8C and cel12B, have been observed with other cellulases from similar sources but for different modes of action such as those of cellobiohydrolase-, CBH1-, and endoglucanaseSpezyme-CP from Trichoderma reesei, reported by Ye et al. (36). The current thermal inactivation findings are consistent with the enzyme thermal stability profiles shown in Fig. 1, above.

\section{Insert Figure 2}

The process of thermal inactivation has been described as an alteration in an enzyme's secondary, tertiary or quaternary structural non-covalent contacts while the corresponding covalent bonds remain intact (37). The process of denaturation is very complex and involves many intermediates, making it difficult to discern which changes result in the loss of activity. Therefore, a simple single-phase, first-order model was chosen for giving functionally useful relative rate constants with which to make the Arrhenius analysis of the three enzymes

The data in Fig. 2 were used in first-order plots of the enzyme activity losses over $24 \mathrm{~h}$ at the defined temperatures for cel8C and cel12B, on $\mathrm{CMC}$, and for peh28, on polygalacturonic acid (plots not shown), from which the corresponding enzyme thermal inactivation rate constants $\left(k_{d}\right)$ were evaluated from the slopes of linear regressions of $\ln \left(\%\right.$ remaining activity) $v s$. time. Table I summarizes the $\mathrm{k}_{\mathrm{d}}$ values as well as half-lives $\left(\mathrm{t}_{1 / 2}\right)$ and decimal-reduction times (D-values).

\section{$\underline{\text { Insert Table I }}$}


Two of the nine traces in Fig. 2 do not show $>50 \%$ loss of activity in 24 h, itself a qualitative indicator of relative thermal stability of those two enzymes compared to the third. First-order decay data out to 2-3 half-lives would have been better, but this was impractical for the systems being studied. Data in Table I indicate the increases in $\mathrm{k}_{\mathrm{d}}$ with temperature were much smaller for cel12B and peh28 (6-fold over the range), unlike cel8C (23-fold over the range). Small changes in $\mathrm{k}_{\mathrm{d}}$ over a similar temperature range are in agreement with those of Naidu and Panda (37) for three pectinases from A. niger, and Saqib et al. (38) for an endoglucanase from A. fumigatus. From this behavior, Naidu and Panda (37) deduced that little conformational change in the enzyme's three-dimensional structure occurred over the temperature range studied.

Similar half-lives were calculated for cel12B and peh28, of approximately 28,10 and $5 \mathrm{~h}$, which were higher than those of cel8C, $9,0.8$ and $0.4 \mathrm{~h}$, at 37,50 and $60^{\circ} \mathrm{C}$, respectively (Table I). Lower half-lives than those for peh28 were reported by Joshi et al. (39) Maisuria et al. (23) and Ortega et al. (25) for polygalacturonases from different sources, at similar temperatures. Similar values were also calculated for the thermally-stable endopolygalacturonase from Achaetomium sp., Strain Xz8, at $50^{\circ} \mathrm{C}(40)$, and for immobilized exo-polygalacturonase (exo-PG) from $P$. notatum, at $60^{\circ} \mathrm{C}(26)$. Values lower than those of cel12B and higher than those of cel8C were reported by Javed et al. (41) and Farinas et al. (42) for the half-lives of other endoglucanases, at similar temperatures. Dutta et al. (43) calculated higher values, by as much as 5- and 17-fold, than those of cel12B for the half-lives of an immobilized cellulase, supplemented with magnesium, from Bacillus subtilis at $50^{\circ} \mathrm{C}$ and $60^{\circ} \mathrm{C}$, respectively. This enzyme in free form, however, had similar half-lives to those of cel12B at 50 and $60^{\circ} \mathrm{C}(43)$. These results, from a kinetic perspective, demonstrate the relative thermal stability of cel12B and peh28, which is further elarified dissected in the following thermodynamic discussion.

\section{Thermodynamic analysis of thermal inactivation of cel12B, cel8C and peh28}


Determination of the thermodynamic parameters of inactivation was carried out for insight into the behavior of the molecules as well as the complexity of the inactivation process across the $37-60^{\circ} \mathrm{C}$ temperature range for cel12B, cel8C and peh28. Activation energy for thermal inactivation (inactivation energy, $\left.E_{d}\right)$, change in entropy $(\Delta S)$, change in enthalpy $(\Delta \mathrm{H})$ and change in Gibbs free energy $(\Delta \mathrm{G})$ are the enzyme parameters calculated (Table II) from Arrhenius plots, Fig. 3, based on the inactivation rate constants (Table I). Linearity in the Arrhenius plots suggests a temperature-dependent mechanism for enzyme inactivation as proposed previously (19).

\section{$\underline{\text { Insert Figure } 3}$}

$E_{d}$ is the energy that must be absorbed by the molecules to initiate enzyme inactivation, to get to the height of the barrier, or transition state, for inactivation, as explained by Sant'Anna et al. (44). $\mathrm{E}_{\mathrm{d}}$ values were calculated as $67.4,121$ and $63.5 \mathrm{~kJ} \mathrm{~mole}^{-1}$ for cel12B, cel8C and peh28, respectively, Table II. Similar values have been previously reported for cellulases/endoglucanases $(29,38,43)$ and polygalacturonases/pectate lyases $(23,26,45)$, from different sources.

\section{$\underline{\text { Insert Table II }}$}

The enzyme and solvent disorder as well as the degrees of solvation and compactness in the protein molecular structure can be inferred through the quantitative analysis of $\Delta \mathrm{S}$ values as reported by Dogan and Tari (46) and Gouzi et al. (47). Table II indicates that the change and/or variation in $\Delta \mathrm{S}$ was negligible across the temperature range for each enzyme. Negative values and temperature-invariance of $\Delta \mathrm{S}$, have been previously reported for several other polygalacturonases/endoglucanases from different sources $(24$, $38,39,43)$. That the enzymes became more ordered upon thermal inactivation has been suggested by Batista et al. (19) as an increased compactness due to formation of ion-pairs ("salt-bridges") as the temperature increases, similar to a report by Naidu and Panda (37). Negative entropies of thermal inactivation have also been attributed to more ordered water molecules at the protein interface (48-50). 
Gibbs free energy is the energy required for the enzyme molecules to undergo the endergonic process of inactivation as defined by Gouzi et al. (47). Table II indicates the differences in $\Delta$ Gs across the temperature range were minimal for each enzyme. Similar observations were found with several heatstable structures $(24,30,37,39)$, which may indicate a decrease in the enzyme lability to unfolding as the temperature increased in the current investigation. The data also show similar $\Delta \mathrm{G}$ values, within experimental error, for the three current enzymes. This finding is in agreement with Dutta et al. (43) who reported similar $\Delta \mathrm{Gs}$ with nano-magnesium-supplemented and non-supplemented immobilized cellulases from B. subtilis, which also showed dissimilar thermal stabilities (manifested in half-lives and/or inactivation energies) across a similar temperature range. This indicates the process of thermal inactivation for cel12B, cel8C, peh28, in the temperature range studied here, must be under kinetic control, i.e.dominated by $\mathrm{k}_{\mathrm{d}} / \mathrm{E}_{\mathrm{d}}$ considerations. Although the $\Delta \mathrm{Gs}$ for the three enzymes are similar, it is instructive to consider their relative enthalpic and entropic contributions: for cel12B and peh28, the entropic contribution accounts for two-thirds of $\Delta \mathrm{G}$, whereas for cel8C, it is the enthalpic contribution which accounts for two-thirds of $\Delta \mathrm{G}$. It is the enthalpic contribution which is directly affected by the kineticallyderived parameter $E_{\mathrm{d}}$.

The degree and/or intensity of the thermal disruption of the noncovalent linkages in enzymes can be predicted through analysis of an enthalpy parameter, $\Delta \mathrm{H}$, a characteristic that is derived from the kinetic parameter $\mathrm{E}_{\mathrm{d}}$. Data in Table II indicate constant $\Delta \mathrm{H}$ across the temperature range for each enzyme. A similar finding was reported for other polygalacturonases/pectate lyases $(45,51)$ as well as endoglucanases/cellulases $(38,43)$. Lower $\Delta \mathrm{Hs}$ were calculated for cel12B and peh28, 64.3 and $61.3 \mathrm{~kJ}$ $\mathrm{mol}^{-1}$, respectively, than for cel8C, $118 \mathrm{~kJ} \mathrm{~mol}^{-1}$. A similar $\Delta \mathrm{H}$ to that of peh 28 was reported by Maisuria and Nerurkar (45), for pectate lyase from $P c c$, while a higher value was reported by Dogan and Tari (46), $149 \mathrm{~kJ} \mathrm{~mol}^{-1}$, for exo-polygalacturonase from $A$. sojae. Similar $\Delta \mathrm{Hs}$ to that of cel12B were calculated by Dutta et al. (43) and Subhedar and Gogate (29), for cel7A from T. reesei and immobilized cellulase from B. subtilis, while Saqib et al. (38) reported a much higher value, $254 \mathrm{~kJ} \mathrm{~mol}^{-1}$, for an endoglucanase from 
A. fumigatus. Small and constant $\Delta \mathrm{Hs}$ with increasing temperature are indicative of an enzyme undergoing relatively less noncovalent bond breakage upon thermal inactivation than for enzymes with large $\Delta \mathrm{Hs}$, according to Batista et al. (19), D'Amico et al. (52) and Vieille and Zeikus (53).

The lower $\Delta \mathrm{H}$ values calculated for cel12B and peh28, relative to cel8C, follow the lower $\mathrm{E}_{\mathrm{d}} \mathrm{s}$ calculated for them. Thus, the rapid inactivation observed for the cel $8 \mathrm{C}$ at temperatures beyond $37^{\circ} \mathrm{C}$ indicates the dominant role of enthalpic connections in accelerating the noncovalent disruptions and, therefore, enzyme inactivation. The dominance of enthalpy in the process of inactivation is evident with some enzymes in aqueous solution (44). In other cases, large positive entropy changes compensate for a high inactivation barrier, thus, lowering the $\Delta \mathrm{G}$ to facilitate the process of inactivation $(54,55)$. Since the degree of enzyme unfolding and the associated non-covalent bond breakage as well as enzyme/solvent disordering at the transition state are directly proportional with the increase in the $\Delta \mathrm{H}$ and $\Delta \mathrm{S}$ values, respectively (25), variation in the $\mathrm{k}_{\mathrm{d}}$-values and the corresponding relative changes in $\Delta \mathrm{S}$ and $\Delta \mathrm{H}$ could be used to infer their contributions to the inactivation processes for the current enzymes (Sant'Anna et al. (44)). In this regard, it is noted firstly that the $\Delta \mathrm{S}$ values for the three current enzymes are substantially negative, with those for the two more kinetically stable enzymes, cel12B and peh28, twice that of cel8C. Secondly, for the two more stable enzymes, the makeup of $\Delta \mathrm{G}$ is two-thirds entropic, one-third enthalpic, whereas the converse contributions obtain for cel8C. Although the three enzymes have the same $\Delta \mathrm{Gs}$ for inactivation, cel12B and peh28 are stabilized entropically, thus, their denaturation requires a substantial amount of free energy extraction from the surroundings in order to achieve the ordering/compaction implicit in the large negative $\Delta \mathrm{S}$, based on Christ and van Gunsteren (54) and Jayachandran et al. (55).

To sum up, the inferior thermal stability of cel8C was evident from its inactivation in the $40-80^{\circ} \mathrm{C}$ range, unlike cel12B and peh28. The contribution of a carbohydrate binding domain in cel12B and the involvement of other amino acid residues are thought to account for its enhanced thermal stability, relative to cel8C. Analogous investigation into a molecular attribution for the thermal stability of peh28 was sought through structural modeling to better understand its survival of elevated thermal high 
exposure at or above $60^{\circ} \mathrm{C}$. The thermal instability of cel8C parallels those of other GH- 8 cellulases. Since the makeup of the Gibbs free energy for the inactivation is two-thirds entropic and one-third enthalpic for cel12B and peh28, stabilities of the two enzymes are entropy-controlled over the temperature range. The substantial survival seen for cel12B and peh28 over $24 \mathrm{~h}$ exposure to 50 and $60^{\circ} \mathrm{C}$ is industrially relevant for such hydrolysis catalysts.

Thus, cel12B and peh28 from the current investigation are suggested for integration with the current competitive market for enhanced production of biofuels. On the other hand, the inferior thermal stability of cel8C would suggest it as a candidate for future genomic/genetic modification for increasing the efficiency towards process optimization for biofuels and other value-added products. The feasibility of using these three enzymes, in concert with a related $\beta$-glucosidase, to generate industrially useful amounts of biofuel precursors, glucose, cellobiose and galacturonic acid from a waste biomass has been shown (12).

\section{Funding}

The study was supported by the Institute for Sustainable Energy and the Environment, Texas A\&M University-Kingsville, United States, in partnership with the Egyptian Ministry of Higher Education, Egypt.

\section{Acknowledgments}

The authors are grateful to Prof. Dr. Shad Nelson, Department of Soil and Plant Sciences, Department of Agriculture, Texas A\&M University-Kingsville and Prof. Dr. Wafaa M. Abd El-Rahim, Professor of Environmental Microbiology, National Research Centre, Egypt for their invaluable contributions on the topic of the research. 


\section{Conflict of Interest}

None declared. 


\section{References}

(1) Vogel, J., Garvin, D., Mockler, T., and et al. (2010) Genome sequencing and analysis of the model grass Brachypodium distachyon. Nature. 463, 763-768

(2) Yang, B., Dai, Z., Ding, S., and Wyman, C.E. (2011) Enzymatic hydrolysis of cellulosic biomass. Biofuels. 2, 421-450

(3) Zhang, X.Z., Sathitsuksanoh, N., and Zhang, Y.H. (2010) Glycoside hydrolase family 9 processive endoglucanase from Clostridium phytofermentans: heterologous expression, characterization, and synergy with family 48 cellobiohydrolase. Bioresource Technol. 101, 55345538

(4) Van Dyk, J.S., and Pletschke, B.I. (2012) A review of lignocellulose bioconversion using enzymatic hydrolysis and synergistic cooperation between enzymes-Factors affecting enzymes, conversion and synergy. Biotechnol.Adv. 30, 1458-1480

(5) Henrissat, B., and Davies, G. (1997) Structural and sequence-based classification of glycoside hydrolases. Curr. Opin. Struct. Biol. 7, 637-644

(6) Eriksson, T., Karlsson, J., and Tjerneld, F. (2002) A model explaining declining rate in hydrolysis of lignocellulose substrates with cellobiohydrolase I (cel7A) and endoglucanase I (cel7B) of Trichoderma reesei. Appl.Biochem.Biotechnol. 101, 41-60

(7) Aguiar-Oliveira, E., and Maugeri, F. (2011) Thermal stability of the immobilized fructosyltransferase from Rhodotorula sp. Braz. J.Chem. Eng. 28, 363-372

(8) Nadeem, M., Perveen, R., Javed, M.R., Nadeem, H., and Rashid, M.H. (2007) Kinetic and thermodynamic properties of novel glucoamylase from Humicola sp. Enzyme Microb.Technol. 41, 558-564

(9) Gummadi, S.N., and Panda, T. (2003) Purification and biochemical properties of microbial pectinases - a review. Process Biochem.. 38, 987-996

(10) Joshi, M., Nerurkar, M., and Adivarekar, R. (2015) Characterization, kinetic, and thermodynamic studies of marine pectinase from Bacillus subtilis. Prep. Biochem.Biotechnol.. 45, 205-220

(11) Sorensen, T.H., Cruys-Bagger, N., Borch, K., and Westh, P. (2015) Free energy diagram for the heterogeneous enzymatic hydrolysis of glycosidic bonds in cellulose. J.Biol. Chem. 290, 2220322211

(12) Ibrahim, E., Jones, K.D., Taylor, K.E., Hosseney, E.N., Mills, P.L., and Escudero, J.M. (2018) Recombinant $E$. coli cellulases, $\beta$-glucosidase, and polygalacturonase convert a citrus processing waste into biofuel precursors. ACS Sus. Chem.Eng. 6, 7304-7312

(13) Ibrahim, E., Jones, K.D., Hosseney, E.N., and Escudero, J. (2013) Molecular cloning and expression of cellulase and polygalacturonase genes in $E$. coli as a promising application for biofuel production J. Pet. Environ. Biotechnol. 4, 147

(14) Ibrahim, E., Jones, K.D., Taylor, K.E., Hosseney, E.N., Mills, P.L., and Escudero, J.M. (2017) Molecular and biochemical characterization of recombinant cel12B, cel8C, and peh28 overexpressed in Escherichia coli and their potential in biofuel production. Biotechnol.Biofuels. 10,52

(15) Nelson, N. (1944) A photometric adaptation of the somogyi method for the determination of glucose. J.Biol.Chem. 153, 375-380

(16) Somogyi, M. (1952) Notes on sugar determination. J.Biol.Chem. 195, 19-23

(17) Miller, G.L. (1959) Use of dinitrosalicylic acid reagent for determination of reducing sugar. Anal. Chem. 31, 426-428

(18) Bhatti, H.N., Asgher, M., Abbas, A., Nawaz, R., and Sheikh, M.A. (2006) Studies on kinetics and thermostability of a novel acid invertase from Fusarium solani. J. Agric. Food Chem. 54, 46174623 
(19) Batista, K.A., Batista, G.L.A., Alves, G.L., and Fernandes, K.F. (2014) Extraction, partial purification and characterization of polyphenol oxidase from Solanum lycocarpum fruits. $J$. Molec. Catal. B: Enzymatic. 102, 211-217

(20) Karlsson, J., Siika-aho, M., Tenkanen, M., and Tjerneld, F. (2002) Enzymatic properties of the low molecular mass endoglucanases Cel12A (EG III) and Cel45A (EG V) of Trichoderma reesei. J. Biotechnol. 99, 63-78

(21) Yeh, Y.F., Chang, S.C., Kuo, H.W., Tong, C.G., Yu, S.M., and Ho, T.H. (2013) A metagenomic approach for the identification and cloning of an endoglucanase from rice straw compost. Gene. 519, 360-366

(22) Narra, M., Dixit, G., Divecha, J., Madamwar, D., and Shah, A.R. (2012) Production of cellulases by solid state fermentation with Aspergillus terreus and enzymatic hydrolysis of mild alkalitreated rice straw. Bioresource Technol.. 121, 355-361

(23) Maisuria, V.B., Patel, V.A., and Nerurkar, A.S. (2010) Biochemical and thermal stabilization parameters of polygalacturonase from Erwinia carotovora subsp. carotovora BR1. J. Microbiol. Biotechnol. 20, 1077-1085

(24) Pan, X., Li, K., Ma, R., Shi, P., Huang, H., Yang, P., Meng, K., and Yao, B. (2015) Biochemical characterization of three distinct polygalacturonases from Neosartorya fischeri P1. Food Chem.. 188, 569-575

(25) Ortega, N., De Diego, S., Rodríguez-Nogales, J.M., Perez-Mateos, M., and Busto, M.D. (2004) Kinetic behaviour and thermal inactivation of pectinlyase used in food processing. Int. J.Food Sci.Technol. 39, 631-639

(26) Amin, F., Bhatti, H.N., Bilal, M., and Asgher, M. (2017) Improvement of activity, thermostability and fruit juice clarification characteristics of fungal exo-polygalacturonase. Int. J. Biol. Macromol. 95, 974-984

(27) Crennell, S.J., Hreggvidsson, G.O., and Nordberg Karlsson, E. (2002) The Structure of Rhodothermus marinus Cel12A, A Highly Thermostable Family 12 Endoglucanase, at $1.8 \AA$ Resolution. J.Molec.Biol. 320, 883-897

(28) Okano, H., Ozaki, M., Kanaya, E., Kim, J.J., Angkawidjaja, C., Koga, Y., and Kanaya, S. (2014) Structure and stability of metagenome-derived glycoside hydrolase family 12 cellulase (LCCelA) a homolog of Cel12A from Rhodothermus marinus. FEBS Open Bio. 4, 936-946

(29) Subhedar, P.B., and Gogate, P.R. (2014) Enhancing the activity of cellulase enzyme using ultrasonic irradiations. J.Molec. Catal. B: Enzymatic. 101, 108-114

(30) Basto, C., Silva, C.J., Gübitz, G., and Cavaco-Paulo, A. (2007) Stability and decolourization ability of Trametes villosa laccase in liquid ultrasonic fields. Ultrason. Sonochem. 14, 355-362

(31) Hall, M., Rubin, J., Behrens, S.H., and Bommarius, A.S. (2011) The cellulose-binding domain of cellobiohydrolase Cel7A from Trichoderma reesei is also a thermostabilizing domain. $J$ Biotechnol. 155, 370-376

(32) Liu, W., Zhang, X.-Z., Zhang, Z., and Zhang, Y.H.P. (2010) Engineering of Clostridium phytofermentans Cel5A for improved thermostability. Appl. Environ.Microbiol. 76, 4914-4917

(33) Wei, Y., Shih, J., Li, J., and Goodwin, P.H. (2002) Two pectin lyase genes, pnl-1 and pnl-2, from Colletotrichum gloeosporioides f. sp. malvae differ in a cellulose-binding domain and in their expression during infection of Malva pusilla. Microbiology (Reading, England). 148, 2149-2157

(34) van Solingen, P., Meijer, D., van der Kleij, W.A., Barnett, C., Bolle, R., Power, S.D., and Jones, B.E. (2001) Cloning and expression of an endocellulase gene from a novel streptomycete isolated from an East African soda lake. Extremophiles. 5, 333-341

(35) Palomaki, T., Pickersgill, R., Riekki, R., Romantschuk, M., and Saarilahti, H.T. (2002) A putative three-dimensional targeting motif of polygalacturonase (PehA), a protein secreted through the type II (GSP) pathway in Erwinia carotovora. Mol. Microbiol. 43, 585-596

(36) Ye, Z., Hatfield, K.M., and Eric Berson, R. (2012) Inactivation of individual cellulase components. Bioresource Technol. 106, 133-137 
(37) Naidu, G.S.N., and Panda, T. (2003) Studies on pH and thermal inactivation of pectolytic enzymes from Aspergillus niger. Biochem.Eng. J. 16, 57-67

(38) Saqib, A.A., Farooq, A., Iqbal, M., Hassan, J.U., Hayat, U., and Baig, S. (2012) A thermostable crude endoglucanase produced by Aspergillus fumigatus in a novel solid state fermentation process using isolated free water. Enzyme Res. 2012, 196853

(39) Joshi, M., Nerurkar, M., and Adivarekar, R. (2015) Characterization, kinetic, and thermodynamic studies of marine pectinase from Bacillus subtilis. Prep. Biochem.Biotechnol. 45, 205-220

(40) Tu, T., Meng, K., Bai, Y., Shi, P., Luo, H., Wang, Y., Yang, P., Zhang, Y., Zhang, W., and Yao, B. (2013) High-yield production of a low-temperature-active polygalacturonase for papaya juice clarification. Food Chem. 141, 2974-2981

(41) Javed, M.R., Rashid, M.H., Nadeem, H., Riaz, M., and Perveen, R. (2009) Catalytic and thermodynamic characterization of endoglucanase (CMCase) from Aspergillus oryzae cmc-1. Appl. Biochem. Biotechnol. 157, 483-497

(42) Farinas, C.S., Loyo, M.M., Baraldo, A., Jr., Tardioli, P.W., Neto, V.B., and Couri, S. (2010) Finding stable cellulase and xylanase: evaluation of the synergistic effect of $\mathrm{pH}$ and temperature. New Biotechnol. 27, 810-815

(43) Dutta, N., Biswas, S., and Saha, M.K. (2016) Biophysical characterization and activity analysis of nano-magnesium supplemented cellulase obtained from a psychrobacterium following graphene oxide immobilization. Enzyme Microb. Technol. 95, 248-258

(44) Sant'Anna, V., Cladera-Olivera, F., and Brandelli, A. (2012) Kinetic and thermodynamic study of thermal inactivation of the antimicrobial peptide P34 in milk. Food Chem. 130, 84-89

(45) Maisuria, V.B., and Nerurkar, A.S. (2012) Biochemical properties and thermal behavior of pectate lyase produced by Pectobacterium carotovorum subsp. carotovorum BR1 with industrial potentials. Biochem.Eng. J. 63, 22-30

(46) Dogan, N., and Tari, C. (2008) Characterization of three-phase partitioned exo-polygalacturonase from Aspergillus sojae with unique properties. Biochem.Eng. J. 39, 43-50

(47) Gouzi, H., Depagne, C., and Coradin, T. (2012) Kinetics and thermodynamics of the thermal inactivation of polyphenol oxidase in an aqueous extract from Agaricus bisporus. J. Agric. Food Chem. 60, 500-506

(48) Zechel, D.L., Boraston, A.B., Gloster, T., Boraston, C.M., Macdonald, J.M., Tilbrook, D.M., Stick, R.V., and Davies, G.J. (2003) Iminosugar glycosidase inhibitors: structural and thermodynamic dissection of the binding of isofagomine and 1-deoxynojirimycin to betaglucosidases. J. Am. Chem. Soc.. 125, 14313-14323

(49) Clarke, C., Woods, R.J., Gluska, J., Cooper, A., Nutley, M.A., and Boons, G.-J. (2001) Involvement of water in carbohydrate-protein binding. J. Am. Chem. Soc. 123, 12238-12247

(50) Dunitz, J.D. (1994) The entropic cost of bound water in crystals and biomolecules. Science (New York, N.Y.). 264, 670

(51) Tari, C., Dogan, N., and Gogus, N. (2008) Biochemical and thermal characterization of crude exo-polygalacturonase produced by Aspergillus sojae. Food Chem. 111, 824-829

(52) D'Amico, S., Marx, J.C., Gerday, C., and Feller, G. (2003) Activity-stability relationships in extremophilic enzymes. J. Biol. Chem. 278, 7891-7896

(53) Vieille, C., and Gregory Zeikus, J. (1996) Thermozymes: Identifying molecular determinants of protein structural and functional stability. Tr.Biotechnol. 14, 183-190

(54) Christ, C.D., and van Gunsteren, W.F. (2009) Simple, efficient, and reliable computation of multiple free energy differences from a single simulation: a reference Hamiltonian parameter update scheme for enveloping distribution sampling (EDS). J. Chem.Theory Comput.. 5, 276-286

(55) Jayachandran, G., Shirts, M.R., Park, S., and Pande, V.S. (2006) Parallelized-over-parts computation of absolute binding free energy with docking and molecular dynamics. $J$. Chem. Phys. 125, 084901 


\section{Legends to the figures}

Fig. 1 Residual activities for cel12B, cel8C on CMC and peh28 on polygalacturonic acid. Residual activities were determined following one-hour incubation of each enzyme at each presented temperature, compared to thermally untreated controls held at $0^{\circ} \mathrm{C}$. One unit of enzyme activity was defined as the amount of enzyme releasing $1 \mu \mathrm{mol}$ of reducing sugars per minute from the substrate under the assay conditions. Values presented are given as a mean of triplicates \pm SE. Reaction mixtures $(1.0 \mathrm{ml}$ incubated $1 \mathrm{~h})$ contained, for peh28: polygalacturonic acid, $4 \mathrm{mg} ; 50 \mathrm{mM}$ acetate buffer at $\mathrm{pH}$ 5.4; enzyme protein, $1.604 \mathrm{mg}$; temperature, $45^{\circ} \mathrm{C}$; and for cel12B and cel8C: CMC, $25 \mathrm{mg}$; $50 \mathrm{mM}$ citrate buffer at $\mathrm{pH}$ 5.4; temperature, $45^{\circ} \mathrm{C}$, with respective enzyme proteins of 0.742 and $0.914 \mathrm{mg}$.

Fig. 2 Thermal inactivation profiles of cel12B (a), cel8C (b) and peh28 (c) at 37,50 and $60^{\circ} \mathrm{C}$. Enzyme residual activities were determined on their respective substrate CMC or polygalacturonic acid under the enzyme optimum assay conditions described below, compared with the same activities using thermally untreated controls. Values presented are given as a mean of triplicates \pm SE. Reaction mixtures $\left(1.0 \mathrm{ml}\right.$ incubated $1 \mathrm{~h}$ at $\mathrm{pH} 5.4$ and $\left.45^{\circ} \mathrm{C}\right)$ contained, for peh28: polygalacturonic acid, $4 \mathrm{mg} ; 50 \mathrm{mM}$ acetate buffer; enzyme protein, $1.48 \mathrm{mg}$; and for cel12B and cel8C: CMC, $25 \mathrm{mg}$; $50 \mathrm{mM}$ citrate buffer, with respective enzyme proteins of 0.706 and $0.881 \mathrm{mg}$.

Fig. 3 Arrhenius plots for cel12B (a), cel8C (b) and peh28 (c) activity losses over 24 h at various temperatures (K). The $\mathrm{k}_{\mathrm{d}}$ is the enzyme thermal inactivation rate constant at each respective temperature, taken from Table I. The enzyme activation energy for thermal inactivation $\left(E_{d}\right)$ was calculated from the slope of the Arrhenius plot; values are presented in Table II, below. 
Figure 1




Figure 2

Figure 3

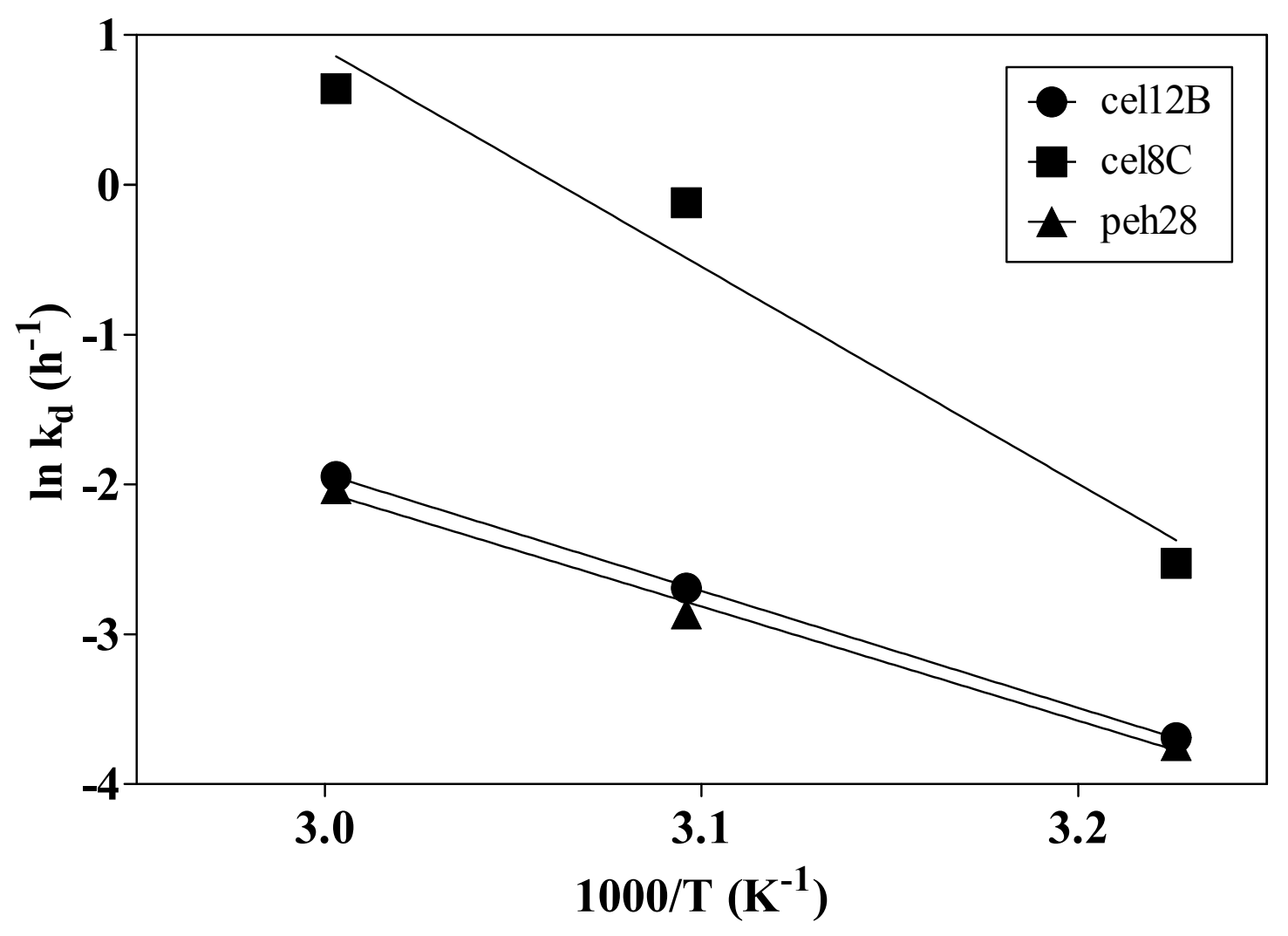


Table I. Kinetic parameters for thermal inactivation of cel12B, cel12B and peh28

\begin{tabular}{|c|c|c|c|c|}
\hline Enzyme & $\begin{array}{c}\text { Temperature } \\
\left({ }^{\circ} \mathrm{C}\right)\end{array}$ & $\begin{array}{c}\mathbf{k}_{d^{a}} \\
\left(h^{-1}\right)\end{array}$ & $\begin{array}{l}\mathbf{t}_{1 / 2}{ }^{b} \\
\text { (h) }\end{array}$ & $\begin{array}{l}D^{\mathbf{c}} \\
\text { (h) }\end{array}$ \\
\hline \multirow[t]{3}{*}{ cel12B } & 37 & $0.025 \pm 0.002$ & 28 & 92 \\
\hline & 50 & $0.068 \pm 0.001$ & 10 & 34 \\
\hline & 60 & $0.15 \pm 0.02$ & 4.9 & 15 \\
\hline \multirow[t]{3}{*}{ cel8C } & 37 & $0.081 \pm 0.001$ & 8.6 & 28 \\
\hline & 50 & $0.89 \pm 0.02$ & 0.8 & 2.6 \\
\hline & 60 & $1.9 \pm 0.1$ & 0.4 & 1.2 \\
\hline \multirow[t]{3}{*}{ peh28 } & 37 & $0.024 \pm 0.001$ & 29 & 96 \\
\hline & 50 & $0.058 \pm 0.005$ & 12 & 40 \\
\hline & 60 & $0.13 \pm 0.01$ & 5.3 & 18 \\
\hline
\end{tabular}

\footnotetext{
${ }^{a}$ Rate constants for the thermal inactivation $\pm \mathrm{SE}$

${ }^{b}$ Enzyme half-life; time required for the enzyme to lose half of its activity

${ }^{c}$ Enzyme decimal-reduction time; time required for the enzyme to lose $90 \%$ of its activity
} 
Table II. Thermodynamic parameters for thermal inactivation of cel12B, cel12B and peh28

\begin{tabular}{|c|c|c|c|c|c|}
\hline Enzyme & $\begin{array}{c}\text { Temperature } \\
\left({ }^{\circ} \mathrm{C}\right)\end{array}$ & $\begin{array}{c}\mathbf{E}_{\mathrm{d}}^{\mathrm{a}} \\
\left(\mathrm{kJ} \mathrm{mole}^{-1}\right)\end{array}$ & $\begin{array}{c}\Delta \mathbf{H}^{\mathrm{b}} \\
\left(\mathrm{kJ} \mathrm{mol}^{-1}\right)\end{array}$ & $\begin{array}{c}\Delta \mathrm{G}^{\mathrm{c}} \\
\left(\mathrm{kJ} \mathrm{mol}{ }^{-1}\right)\end{array}$ & $\begin{array}{c}\Delta \mathbf{S}_{\mathrm{t}}^{\mathrm{d}} \\
\left(\mathrm{J} \mathrm{mol}^{-1} \mathrm{~K}^{-1}\right)\end{array}$ \\
\hline \multirow[t]{3}{*}{ cel12B } & 37 & $67.4 \pm 0.4$ & 64.4 & 192 & -412 \\
\hline & 50 & & 64.3 & 197 & -412 \\
\hline & 60 & & 64.2 & 202 & -413 \\
\hline \multirow[t]{3}{*}{ cel8C } & 37 & $121 \pm 5$ & 118 & 189 & -228 \\
\hline & 50 & & 118 & 191 & -224 \\
\hline & 60 & & 118 & 194 & -229 \\
\hline \multirow[t]{3}{*}{ peh28 } & 37 & $63.5 \pm 1.8$ & 61.2 & 192 & -422 \\
\hline & 50 & & 61.4 & 198 & -423 \\
\hline & 60 & & 61.3 & 202 & -422 \\
\hline
\end{tabular}

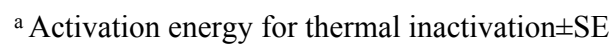

${ }^{\mathrm{b}}$ Change in enthalpy

${ }^{c}$ Change in Gibbs free energy

${ }^{\mathrm{d}}$ Change in entropy 